\title{
An Introduction To Cost-Of-Living Adjustments In Public Retirement Plans: Details Matter
}

Penelope R. Jennings, J.D., California State University, Northridge, USA William P. Jennings, Ph.D., California State University, Northridge, USA G. Michael Phillips, Ph.D., California State University, Northridge, USA

\begin{abstract}
While financial planning students are expected to be able to understand client retirement plans, subtle differences in cost-of-living adjustments can have major impact on the success of client retirement plans. This teaching note compares the cost-of-living adjustments in the largest government sponsored retirement systems and a hypothetical traditional privately sponsored plan. Using a Monte Carlo simulation, we estimate the impact on retirement experience from the different COLAs. These differences are large, with differing protection from future inflation and differing risk for running out of money during retirement. This teaching note will help instructors address Certified Financial Planner (CFP) Board Learning Outcome G.52 "Retirement Needs Analysis". The material may also be used in economics, human resources, public administration, and other classes addressing policy aspects of retirement plans.
\end{abstract}

Keywords: Cost-Of-Living Adjustments; Defined Benefit Plans; Inflation; Public Employee Retirement Systems

\section{INTRODUCTION}

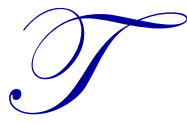

his is a teaching note about an often overlooked but extremely important detail in defined benefit retirement systems, the cost-of-living adjustments and how they are calculated. This topic is not covered in most financial planning textbooks, except perhaps for a mention of their existence. Differences between COLA clauses in different retirement plans, however, will be shown to have substantial potential impact on the value of those plans to retirees over time. The three public retirement plans we consider include over 4,000,000 members and the fourth, Social Security, currently provides retirement benefits to over 40,000,000 members. The material in this teaching note is of primary importance to instructors in finance and financial planning, but may also be of use in selected economics, human resources, public administration, and business law courses.

While the current economy is not struggling with inflationary pressures, from time to time these can appear and have significant impact on the long term success of retirement plans. Because of this, the Certified Financial Planners Board of Standards "Student-Centered Learning Objectives based upon CFP Board Principal Topics (rev 2015)" (CFP Board, 2016) specifically identifies the effects of inflation on retirement cash inflows as a key point in its learning objective G.52 "Retirement Needs Analysis".

At one time, traditional defined benefit (DB) pension plans with cost-of-living adjustments provided some inflation protection for retirees. One popular financial planning textbook advises "You should also consider whether the plan includes a regular cost-of-living adjustment (COLA) to the benefit you receive. Although your in itial benefit might be plenty to live on, inflation will gradually make it more difficult to make ends meet. Many DB plans don't promise specific COLAs." (Bajtels mit, 2006) However, defined benefit plans are quickly disappearing from the private sector and are increasingly a feature just of public employment. Bureau of Labor Statistics research (Wiatrowski, 2012) reports that traditional pensions, including those with cost-of-living allowances, are found in only $10 \%$ of all private sector establishments while $78 \%$ of public employees are covered by such plans. 
The difference in the buying power of retirement income between defined benefit plans with COLA clauses and other plans is important for financial planning students, practicing financial planners, and instructors in financial planning and finance programs to understand. According to the Congressional Research Service, using data from the U.S. Current Population Survey, approximately 16\% of U.S. workers are employed by the public sector (CRS, 2014) and most of these are covered by a defined benefit plan. As early as 2000, economists in the Bureau of Labor Statistics Office of Employment Projections were estimating that about half of public employees were "Baby Boomers" and nearing retirement (Dohm, 2000). Currently, this suggests that there could be as many as 2,000 retirees a day with public employee retirement plans.

As part of their training in required financial planning courses, students in the nearly 400 CFP Board Registered Programs at U.S. universities are required to understand pension plans and the characteristics of retirement income including the impact of inflation. Public retirement systems receive little attention in popular textbooks and references (e.g., Bajtels mit (2006), Tyson (2012), Garman \& Forgue (2015), Milevsky (2012), Hallman \& Rosenbloom (2009), Horan (2009)). On the one hand, it may appear to students that large public employee retirement systems are alike. On the surface these plans seem similar, yet there are subtle yet important differences in cost-of-living adjustment (COLA) provisions, differences that are not addressed in popular personal finance textbooks and references and about which financial planning capstone, retirement planning, and person al financial planning instructors should be aware of for use in classroom discussion.

In the following discussion, we illustrate for financial planning students, their professors, and others interested in teaching about public pensions how even the existence of a COLA can result in strikingly different results depending on how the COLA is constructed. We illustrate how in inflationary times having any COLA is of great value when compared to those retirement plans without one. Besides its use as a teaching resource for financial planning capstone, retirement, and personal finance courses, this teaching note can serve as a resource for business students as well as financial planners, accountants, and other professionals who are concerned with retirement planning and for those reviewing public policy regarding reorganization of public pension plans.

In this discussion, we analyze the cost-of-living adjustment methods used by the three largest public employee retirement systems, the U.S. Social Security system, and a "vanilla" retirement plan without a COLA clause. Public plans considered include the California Public Employees' Retirement System (CalPERS) which benefits approximately $1,815,700$ members in California and has approximately $\$ 300 \mathrm{bb}$ under manage ment (CalPERS 2016), the Civil Service Retirement System (CSRS) which is an older system benefiting many federal employees, and the Federal Employees Retirement System (FERS) which is a newer system for federal employees. Together, these two federal systems cover approximately $90 \%$ of the federal civilian workforce, with 2,400,000 members (U.S. Census, 2014) and almost \$1trillion under management. We also consider a fourth cost-of-living adjustment method, that employed by the U.S. Social Security System. The Social Security System, which covers most workers in the United States, has about 40,000,000 current recipients and almost \$3 trillion invested in the Social Security trust fund (SSA, 2016).

We begin with a brief introduction to the representative government-sponsored pension plans particularly focusing on their COLA characteristics. We then describe our analytical method, called a Monte Carlo simu lation, that we use to evaluate the impact of variations in COLA clauses. We then present and describe the results and a discussion of several implications from these findings. We conclude with a discussion of several classroom applications and overall observations.

\section{Introduction to Representative Government Sponsored Retirement Plans}

Typical academic classes on pensions primarily focus on plans that employers might offer to their employees. From an employee's perspective, traditional "defined benefit" pension plans generate a fixed annual benefit following a company-specific formula. Often the benefit is the product of the employee's final-year salary or an average of some number of years of salary, the total number of cred ited years of employ ment, and a company specific factor such as $2 \%$ per year of service. For example, an employee working at a firm for 30 years who retires with a salary of $\$ 100,000$ might expect a defined benefit payment of $\$ 100,000 \times 30 \times 2 \%=\$ 60,000.00$. 
The computation of benefits by multiplying a base wage by a number of years of service is common in private and public retirement plans. However, in stark contrast to government sponsored retirement plans, the few remaining private plans tend not to offer cost-of-living allowances (Butrica, 2009). In the rest of this section, we provide a brief introduction to the Social Security system, which is the largest retirement system in the U.S., the CalPERS system, which is the largest state or local government sponsored system in the U.S., and the two primary federal civilian retirement plans.

\section{Social Security}

As detailed in Social Security Administration (2016), Social Security provides a variety of benefits for working Americans, including retirement, disability, death, medical, and spousal and survivor benefits. The most financially important of these benefits is the Social Security retirement benefit that allows workers and their spouses to begin collecting retirement benefits at age 62 or later. The retirement benefits are based on a formula of the best annual earnings over thirty-five years. The decision about when to begin taking Social Security benefits is complicated and calls for careful consideration, often with the advice of counselors and financial planners.

The Social Security trust fund currently has nearly $\$ 3$ trillion under management and provides retire ment benefits to nearly 40,000,000 people.

The calculation of annual cost-of-living adjustments is straightforward. The COLA is the percentage increase in the Consumer Price Index for Urban Wage Earners and Clerical Workers (CPI-W) from the third quarter of the last year a COLA was determined to the third quarter of the current year. If there is no increase, there is no COLA. The intent of the Social Security COLA is to provide an annual increase in benefits sufficient to maintain the real purchasing power of the retiree, assuming the CPI-W reflects their expenditures.

A detailed explanation of the Social Security systemand its benefits is available at www.SSA.gov.

California Public Employees’ Retirement System

The California Public Employees' Retirement System (CalPERS) manages pension and health benefits for more than 1.8 million California state, county, and municipal public employees, retirees, and their families. As detailed in CalPERS (2016), CalPERS also provides death, disability, health, and other benefits to covered employees and their families. The CalPERS pension plan is the largest state or local public employee pension plan with about $\$ 300$ billion in investments in 2016. The benefit formula for determining initial retirement benefits is based on years of service credit, age at retirement, and final compensation. Retirement formulas vary based on the member's employer, occupation, and provisions in the contract between CalPERS and the specific employer. Examples of the variety of plans are those offered to employees of various cities and counties and specific plans for judges, members of the legislature, highway patrol and other safety workers, and employees of the California State University System. The average annual benefit in 2015 for a CalPERS retiree was approximately $\$ 28,000$.

The most common cost-of-living adjustment used by CalPERS provides for annual increases of either $2 \%$ per year since retirement or inflation since retirement, whichever is less. The rate of inflation is the percent change in the Consumer Price Index for All Urban Consumers (CPI-U) for the previous calendar year. Because employees retire in different years, to determine the applicable COLA percentage, CalPERS compares the actual rate of inflation to the annual $2 \%$ adjustment, compounds each series, and keeps a running total each year.

In addition to the annual cost-of-living adjustment, CalPERS retirees may receive a related Purchasing Power Protection Allowance (PPPA) to protect them from significant inflationary changes over time that reduce the purchasing power of their benefits below $75 \%$ of their in itial real benefits. For many current and future retirees, this annual adjustment may never take place. As long the annual cost-of-living adjustments are sufficient to maintain real purchasing power of at least $75 \%$ of their initial retirement benefit, there is no PPPA adjustment.

A detailed explanation of the CalPERS systemand its benefits is available at www.CalPERS.ca.gov. 


\section{Civil Service Retirement System (CSRS) \& Federal Employee Retirement System (FERS)}

The Civil Service Retirement System (CSRS) provides retirement, dis ability, and survivor benefits for most civilian employees of the federal government hired before 1984. The CSRS is a defined benefit plan with initial retirement benefits based on age, highest three-year average pay, and years of service. The CSRS was available to most federal civilian employees prior to 1983 and since then, its active membership has been decreasing as its membership dies.

The Federal Employees Retirement System (FERS) was created for federal civilian employees hired after 1983. FERS is a retirement plan that provides benefits from three different sources: a basic defined benefit plan (called the Basic Benefit), Social Security, and the Thrift Savings Plan (TSP). Similar to other public employee plans, the benefit of the defined benefit portion is based on highest three-year average salary, age, and years of service. The FERS formula uses a smaller annual multiplier coordinated with Social Security benefits. Note that while the defined benefit portion is s maller than many other public employee plans, FERS retirement also includes a Thrift Savings Plan (a defined contribution plan) with annual employer contributions.

The COLA for CSRS is the same as for the Social Security COLA. It is based on the most recent third quarter (July-September) compared to the most recent quarter upon which an increase was based. If consumer prices, as measured by the CPI-W, do not increase fro $m$ the third quarter of one year to the third quarter of the next year, there is no COLA under either plan.

The COLA formula for FERS uses the same third-quarter-to-third-quarter annual inflation rate that is utilized by the Social Security and CSRS plans. However, it has a twist that causes federal participants to gradually los e real retirement income in periods of higher inflation. When the inflation rate is less than $2 \%$, the adjustment equals the inflation rate. When the inflation rate is from $2 \%$ to $3 \%$, the adjustment is capped at $2 \%$. When the inflation rate is greater than $3 \%$, the adjustment is the inflation rate less $1 \%$. For example, were the inflation rate $4.5 \%$, then the COLA would be $3.5 \%$

The details of retirement and cost-of-living adjustments for CSRS and FERS are described in the Office of Personnel Management (2016) and at www.OPM.gov.

\section{Method: A Monte Carlo Framework for Understanding COLAs}

Reading algebraic formulas provided by retirement plan sponsors may be of limited use to financial planning students and their prospective clients when it comes to understanding the real impact of inflation adjustments. To better understand the impact and importance of the different COLA clauses, we utilize a popular methodology known as a "Monte Carlo" study (e.g., Asmussen \& Glynn (2007), W inston (1998), McLeish (2005)). In a Monte Carlo study, a computer model is created which depends on random variables. The model is evaluated with a set of values for the random variables and the results are saved for later analysis, a step known as an iteration. A new set of random values is generated for each new iteration and the computer model is re-evaluated with the new results saved. This process is repeated many times for many iterations. When the basic simulation runs are completed, the statistical distribution and characteristics of the Monte Carlo iterations are computed and the resulting histogram and summary statistics provide insight into the statistically anticipated range of future outcomes. Of course, to the extent that the random components of the model do not represent reality, the Monte Carlo results may be inaccurate.

In order to compare the effectiveness of these pension plans in shielding retirees from the potentially negative effects of in flation, we created a Monte Carlo study of 1,000,000 "average experiences" with randomly drawn initial retirement years and randomly drawn duration of retire ment for each iteration. Rather than using a theoretical statistical distribution for each random variable, we utilized a type of analysis called "resampling" in which the observed past values of variables define potential future values. In each iteration, a random pull is made from past observations so each past value might show up again in proportion to its historical frequency. This sampling is done with replacement so that it is theoretically possible, though unlikely, that a single observation would be repeatedly selected (e.g., Good (2006)). More commonly, the results of a resampling -based Monte Carlo simulation reflect the underlying population parameters. The resampled data are drawn from the actual inflation and plan experiences for retirees from the period 1947 to 2015. The Consumer Price Index information is from the Bureau of Labor Statistics (2016). 
To understand the impact of retirement year and life expectancy on the model, we make assumptions about inflation over a retiree's benefit period. We also make assumptions about when the retiree begins receiving benefits and how long the retiree continues to receive benefits. Random values for retirement years and the length of retirement were computed using Excel's "RandBetween" uniform random number function.

The specific Monte Carlo simulation implementation provides a numerically efficient way to see the range of possible outcomes and may be viewed as a generalized "what if" analysis. The particular simulation discussed here was performed using Frontline Systems’ Analytics Solver Platform in Excel 2013.

While one might build more complex retirement models, exploring factors such as gender or racial differences, differences in geographic cost-of-living, or differences in health conditions, it is not at all obvious that adding such complexity to this model would enhance students' understanding of the differences brought about by the different definitions of COLAs in the largest public pension plans or even provide any particular improvement in the overall model. While assessing more complex modeling could be the subject of other research, this particular model was constructed to include a basic set of variables for adequate richness without exces sive complexity.

\section{RESULTS}

In this Monte Carlo simulation, each iteration matches the modeled experience of a hypothetical retiree. For each of the million random trials, the final-year benefits were computed for each of the plans (Social Security, CalPERS, CSRS, FERS, and the hypothetical private traditional plan). The one million estimates of final-year benefits were then compared by computing ratios (e.g., the ratio of CSRS to FERS final benefits) which we re then averaged across all the trials.

The mean and median for these ratios, shown below, demonstrate the relative cost-of-living adjustments between the plans. The "fully-adjusted" COLA performed much better than the partially-adjusted public plans, but all the plans with COLA features performed far better than plans without COLA features. CSRS and Social Security show a Monte Carlo average .13 (or 13\%) better than FERS and .12 (or 12\%) better than PERS (and medians $8 \%$ better than FERS and $9 \%$ better than PERS). FERS and PERS provide about the same benefit. Compared to the fully adjusted CSRS and Social Security plans, the typical private plan without COLA features received on average $60 \%(65 \%$ median) of the final buying power because of historical inflation.

Table 1. Ratios of final retirement benefit comparisons based on one million random trials ("Monte Carlo" simulation)

\begin{tabular}{l|c|c}
\hline \multicolumn{1}{c}{ Ratios of Final Benefits, for Typical Retirements } & Average & Median \\
\hline CSRS \& Social Security to FERS & 1.13 & 1.08 \\
\hline CSRS \& Social Security to PERS & 1.12 & 1.09 \\
\hline FERS to PERS & 0.99 & 1.00 \\
\hline "No COLA" Pension to CSRS \& Social Security & 0.60 & 0.65 \\
\hline "No COLA" Pension to FERS & 0.64 & 0.71 \\
\hline "No COLA" Pension to PERS & 0.64 & 0.71 \\
\hline
\end{tabular}

The Social Security and CSRS plans fully adjust for measured changes in the consumer price index and protect retirees from increases in consumer prices over time. Table 1 presents a comparison between Social Security and CSRS, and FERS and PERS. This comparison shows that the latter plans do not fully adjust for inflation. Whether the hypothetical retiree was enrolled in either PERS or FERS, real inflation-adjusted benefits lost, on average, about $10 \%$ of their initial purchasing power by the retiree's final year.

More dramatically, a "No COLA" private retirement plan suffered a large loss of purchasing power by the retiree's final year absolutely and when compared to the three public employee plans. A "No COLA" lost about $40 \%$ of its initial purchasing power. By contrast, a CSRS or Social Security retiree lost $0 \%$ over the same period. While two employees with different COLA plans might start with the same in itial pension purchasing power, if their plans have different inflation protection, their real purchasing power may diverge significantly over time. 


\section{Some Implications}

Based on the one million sample experiences from the Monte Carlo model of these different cost-of-living adjustments, it is apparent that having COLA protection is vital to preserving purchasing power of retirement income. The "No COLA" pension payments of final benefits were, on average, less than $2 / 3$ of the corresponding public pension final benefits with COLA clauses. The nature of the COLA adjustment is also important. Social Security and CSRS maintain real income over time, providing a final benefit about $10 \%$ greater than FERS or CalPERS.

Both FERS and CalPERS include non-intuitive caps on cost-of-living adjustments. FERS offers a laddered haircut ultimately resulting in its payments trailing inflation by $1 \%$ per year in high inflation years but the actual adjustment is provided on a year-by-year basis. The CalPERS adjustment is made each year to the in itial retirement base, and is capped at an annual adjustment of $2 \%$ per year but with an additional "purchasing power protection allowance" that maintains real income at $75 \%$ or more of the base-year value. As it happens, both of these approaches provided similar results over time in our simulation.

Following the CFP Learning Objectives and the Uniform Prudent Investors Act (Chong, 2015), we believe that best practice would have the retiree's financial plan and the financial planner's advice focus on building a retirement portfolio designed to mitigate any adverse effects of inflation, including investments in stocks, inflation indexed bonds, and real estate. Such mitigation can be done in several ways.

Retirees with "No COLA" plans and their financial planners should recognize the need for additional savings and investments before retiring to help mitigate against potential loss of purchasing power. One financial strategy that students should consider is to layer tax-advantaged 401(k), IRA, Roth IRAs or other investments sufficient as "completion portfolios" when potential clients do not have cost-of-living adjustments in their plans. These completion portfolios should be constructed to provide adequate funding, not just for the first few years of retirement, but for the entirety of the client's retirement.

For retirees with pension plans fully or largely protected from inflation, other savings and investments can be focused more on addressing other retirement concerns and goals including protection from future medical expenses, travel, and desires to provide for heirs. From a financial planning point of $\mathrm{v}$ iew, inflation protected pension plans can be viewed as the investment equivalent of inflation-protected bonds and therefore the balance of the retiree's investments can, and probably should, be more heavily weighted towards non-bond investments.

For those who do not have adequate resources to fund additional retirement vehic les, two possible solutions include working longer to reduce the reliance on retirement funds while increasing the value of eventual Social Security benefits and whatever pension is in place, and adjusting lifestyles to permit savings even while drawing pensions to fund later years' needs.

\section{Teaching Suggestions}

Contemporary students may not have a good understanding of the impact of inflation and the erosion of real income in inflationary times. A first exercise would be to have students determine the buying power of $\$ 1$ when their great grandparents, grandparents, and parents were their age. A convenient resource for this is at http://www.bls.gov/ data/inflation_calculator.htm (BLS, 2016), which permits students to see, for instance, that $\$ 1000$ in 1920 would have the same buying power as $\$ 11,855$ in 2016 . Similarly, one could see that a retiree with $\$ 50,000$ retirement in 1980 would need to have at least $\$ 144,000$ now for corresponding buying power; those without COLAs would now have about a third of their at-retirement buying power.

Another useful exercise would be to consider the impact of a blended retirement with $75 \%$ coming from a pension and $25 \%$ from a retirement account invested in a stock market index. Similarly, financial planning instructors could discuss the applications of insurance-based products such as annuities with inflation riders as supplemental retirement vehicles. 
About $84 \%$ of new and prospective American retirees do not have COLA-clauses in their retirement plans. Consequently, there is also potential for discussion about pension structures in many classes besides financial planning related courses. One discussion topic could focus on an observation by the American Institute of Cert ified Public Accounts (2015) that a common fear of many retirees is running out of money before they die.

An empirical assignment for students would be to explore how well broad-based mutual funds, such as Dimensions Core Equity Fund (DFEOX) or Fidelity's Magellan Fund (FMAGX) maintain their value relative to the CPI.

\section{CONCLUSIONS}

This paper has demonstrated the importance of cost-of-living adjustments in maintaining real retirement income. For those private pension participants without COLA protection, it is essential that they participate in equity-based or annuity-based supplemental investing or retirement systems (e.g., 401(k), Roth IRA plans) to offset some of the inflation loss over time. This paper also suggests that as the public debate about the disappearance of private pensions continues, the focus should be on pensions with COLA rather than pensions without COLA. The extent to which transferring assets from defined benefit plans to defined contribution plans alters inflation risk, is a topic for additional research.

This paper also illustrates the value of the $100 \%$ inflation adjustment to Social Security recipients as compared to less inflation-protected plans. For many public pension participants, the choice to participate or not in Social Security must include consideration of the inflation protection offered.

Finally, it is important for students, financial planners, and even professors planning their own retirements to be aware of the importance of COLA clauses. The fear of outliving one's retirement income, frequently discussed in terms of defined contribution plans subject to market fluctuations, is also a concern for private pension recipients without COLA clauses. Having a defined benefit retirement plan may sound better than a 401(k) or other defined contribution plan, but the details matter.

\section{AUTHOR BIOGRAPHIES}

Penelope R. Jennings, Associate Vice President Emeritus and Professor of Business Law, at California State University, Northridge. She received an A.B. in Political Science and Spanish at the University of California, Davis and a J.D. at UCLA. She is currently serving as Special Assistant to the Provost for Academic Personnel at CSUN.

William P. Jennings, Dean Emeritus and Profess or of Finance, Financial Planning, and Insurance, California State University, Northridge. He also currently serves as a Director of the Center for Computationally Advanced Statistical Techniques, in Pasadena, where he specializes in risk measurement, risk management and investments. He received his M.A. and Ph.D. in Economics from UCLA.

G. Michael Phillips, Profess or of Finance, Financial Planning, and Insurance, and Director of the Center for Financial Planning and Investment, California State University Northridge. He also currently serves as President and Chief Scientist of the Center for Computationally Advanced Statistical Techniques, in Pasadena, where he specializes in statistics, risk measurement, risk management and investments. He received his M.A. and Ph.D. in Economics from the University of California San Diego.

\section{REFERENCES}

American Institute of Certified Public Accountants (AICPA). (2015, first quarter). Retrieved from https://www.aicpa.org/ interestareas/personalfinancialplanning/community/downloadabledocuments/q1-2015-pfp-trends-exec-summary.pdf.

Asmussen, S. and P. Glynn. (2007). Stochastic Simulation: Algorithms and Analysis. New York, New York: Springer Science + Business Media, LLC.

Bajtelsmit, V. (2005). Personal Finance. U.S.A.: John Wiley and Sons, Inc.

Bureau of Labor Statistics (BLS) consumer price index tables. (2016, January 16). Retrieved from http://www.bls.gov/cpi/.

Bureau of Labor Statistics inflation calculator. (2016). Retrieved from http://www.bls.gov/data/inflation_calculator.htm.

Butrica B., Iams, H., Smith, K., and E. Toder. (released October 2012). “The Disappearing Defined Benefit Pension and Its 
Potential Impact on the Retirement Incomes of Baby Boomers,” Social Security Bulletin, Vol. 69, No. 3 (released October 2009).

CalPERS employee retirement information. (2016, January 15). Retrieved from http://www.calpers.ca.gov/.

Certified Financial Planner (CFP). (2016). Retrieved from http://cfp.net/docs/for-education---resources-for-registeredprograms/cfpboard_learning_objectives_resource_document.pdf.

Chong, J, Jennings, P., and G. M. Phillips (2015) “An Overview of Fiduciary Standards and Suitability for Financial Planning Students," American Journal of Business Education, Vol. 8, No. 2 (2015).

Dohm, A. (2000) "Gauging the Labor Force Effects of Retiring Baby-Boomers," Monthly Labor Review (2000, July).

Garman, E. and R. Forgue. (2015). Personal Finance. Boston, U.S.A.: Cengage Learning.

Good, P. (2006). Resampling Methods. $3^{\text {rd }}$ Ed. Boston, U.S.A.:Birkhauser.

Hallman, G. and J. Rosenbloom. (2009) Private Wealth Management. Eighth Ed. United States: John Wiley and Sons, Inc.

Horan, S. Private Wealth. (2009) CFA Institute. United States: John Wiley and Sons, Inc.

Milevsky, M. (2012) The 7 Most Important Equations for Your Retirement. United States: John Wiley and Sons Inc.

McLeish, D. (2005). Monte Carol Simulation \& Finance. Hoboken, New Jersey: John Wiley and Sons, Inc.

Office of Personnel Management (OPM) retirement information on CRS and FERS. (2016, January 16) Retrieved from https://www.opm.gov/retirement-services/fers-information/computation/.

Social Security Administration (SSA) retirement benefit information. (2106, January 16). Retrieved from https://www.ssa.gov/ news/cola/. 15 Jan. 2016.

Topokeski, J. (2014). "Worker Participation in Employer-Sponsored Pensions: A Fact Sheet." Congressional Research Service, March 26, 2014.

Tyson, E., (2012). Personal Finance for Dummies. $7^{\text {th }}$ ed. United States: John Wiley and Sons Inc.

U.S. Census Bureau. (2014) 2014 Annual Survey of Public Employment and Benefits, March 2014. Retrieved from http://www.census.gov./govs/apes/.

Wiatrowski, W. (2012) “The Last Private Industry Pension Plans: A Visual Essay.” Monthly Labor Review, December 2012.

Winston, W. (1998) Financial Models Using Simulation and Optimization. New Field, New York: Palisade Corporation. 